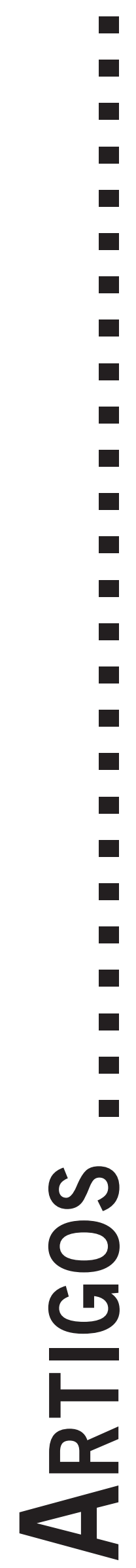




\title{
VIOLÊNCIA DOMÉSTICA PRATICADA POR HOMENS DETIDOS NA DELEGACIA DA MULHER DE BELÉM
}

\author{
Domestic Violence in Men Detained in the Police Women of Belém
}

Violencia Domestica en los Hombres Detenidos en la Comisaria de la Policia de la Mujer de Belém

Adelma Pimentel

\begin{abstract}
Resumo: Pesquisa qualitativa sobre os processos de subjetivação e as percepções da violência conjugal praticada por detentos retidos na Delegacia da Mulher. Questões: o que define masculinidade? Quais modelos orientaram a formação da masculinidade? O que gostou e o que não gostou de aprender com os modelos? Qual a importância do pênis para a virilidade? Qual o valor da afetividade para a relação conjugal? E sobre violência, a concepção dos informantes. Aplicados 10 questionários a homens com escolaridade fundamental, primeiro e segundo graus, todos incompletos. Procedimentos: pesquisa bibliográfica, documental, observação participante, consentimento de pesquisa e entrevista aberta com os detentos. Dados apresentados através do uso de código com letras e números: Q1 até Q10. Análises: cotejamos os dados à literatura sobre masculinidade e violência na medida das possibilidades hermenêuticas. Organização por temáticas. Resultados: a mãe como modelo exclusivo para seis informantes; sobre a violência conjugal ênfase para a modalidade física, o que sugere que fez parte do processo de socialização dos informantes; a violência psicológica também foi bastante citada. Conclusão: a percepção de masculinidade dos informantes é, ainda, orientada pela ótica patriarcal; a violência doméstica é uma pratica não reduzida pela repercussão da Lei nº $11340 / 06$ ou Lei Maria da Penha.
\end{abstract}

Palavras-chave: Masculinidade; Violência Doméstica; Lei Maria da Penha; Delegacia da Mulher.

Abstract: Qualitative research that reflects on the subjective processes and perceptions of domestic violence by detainees held at the Police Office for Women. The questions addressed were: what defines manhood? What models guided the formation of masculinity? What you liked and did not like to learn with models? How important is penis virility? What is the value of affection for the marital relationship? And violence was asked about the design of the informants. 10 questionnaires were administered to men with elementary schooling, first and second degree, all incomplete. Procedures we performed literature search, documentation and participant observation, obtaining the signature of the directors of the institution and subject to the consent search and open interviews with detainees who were willing to participate. Data are presented by using a code that includes both letters and numbers: Q1 to Q10. To collate the data analysis to the literature on masculinity and violence to the extent possible hermeneutic. The organization of the data was thematic. Results: the mother as a unique model for six informants; emphasis on domestic violence to the physical modality, which suggests that it was part of the socialization process of the informants, psychological violence was also quite cited. Conclusion: the informants' perception of masculinity is still guided by the patriarchal perspective, domestic violence is a common practice not diminished by the passing of Law No. 11340/06 or Lei Maria da Penha.

Keywords: Masculinity; Domestic Violence; Law Maria da Penha; Police Office for Women.

Resumen: La investigación cualitativa que se refleja en los procesos de subjetivación y las percepciones de la violencia domestica practicada por los reclusos de la Comisaria de la Policía de la Mujer. Los temas abordados fueron: lo que define la virilidad? ¿Qué modelos direccionaran la formación de la virilidad? ¿ Lo que les gustaba y no le gustaba aprender con modelos? ¿Cuál es la importancia de penis para la virilidad? ¿Cuál es el valor de la afectividad para la relación conyugal? Y se le preguntó acerca de la violencia em la concepción de los informantes. 10 cuestionarios fueron administrados a los hombres con educación primaria, primer y segundo grado, todos incompletos. Procedimientos: investigación bibliogrfica, documental y observación participante; para conseguir la firma de los oficiales de las instituciones de los sujetos al consentimiento a la investigación y entrevistas abiertas con los detenidos que estaban dispuestos a participar. Datos presentados hasta a través de la utilización de un código que incluye letras enmeros: Q1 atQ10. Reunir los datos del análisis de la literatura sobre la masculinidad y la violencia en la medida posible hermenuticas. Organización de los datos por tematicas. Resultados: la madre como modelo exclusivo para seis informantes; sobre la violencia domestica el énfasis para la modalidad física, lo que sugiere que él era parte del proceso de socialización de los informantes; la violencia psicolgica también fue mucho citada. Conclusión: la percepción de la virilidad de los informantes es, ainda, direccionada por la óptica patriarcal; la violencia domestica es una práctica común no reducida por la repercusión de la Ley n 11340/06 o Ley Maria de la Penha.

Palabras-clave: Virilida; Violência Domestica; Ley Maria da Penha; Comisaria de la Policía de la Mujer. 


\section{Introdução}

Este texto oferece reflexões de resultados da coleta de dados referentes à pesquisa "Masculinidades, feminilidades e violência conjugal” realizada em 2009, no Mestrado em Psicologia da Universidade Federal do Pará, cujo objetivo geral do estudo foi examinar as práticas violentas que ocorrem entre o casal no horizonte de uma educação de gênero patriarcal. $\mathrm{O}$ contexto empírico foi a Delegacia da Mulher de Belém do Pará.

A perspectiva da educação de gêneros ${ }^{1}$ é uma referência ampla que permite questionar, compreender e ressignificar as orientações contidas na socialização informal (famílias) e escolar de meninos que provêem para manter ou atualizar a interação (hierarquia ou equidade) entre homens e mulheres. A abordagem crítica-reflexiva também visa contribuir para a des-naturalização das construções do masculino e do feminino, sob o recorte de gênero, da violência sofrida e discriminações (Conrado, 2001). Consideramos que os processos de subjetivação de gêneros constituem uma polaridade integrada, ou seja, a educação contém elementos culturais comuns, sobretudo as diretrizes derivadas do patriarcado moderno, porém no limite do texto me atenho ao exame de aspectos presentes nas aprendizagens informais da masculinidade,

El 10 de diciembre de 1948, la Asamblea General de Naciones Unidas proclamó la Declaración Universal de los Derechos Humanos. En la Declaración Universal de los Derechos Humanos se halla la primera mención a la igualdad de derechos sin distinción de sexos, al igual que se establece el derecho a la vida, a la libertad y a la seguridad de la persona y se establece que nadie será sometido a torturas ni a penas o tratos crueles, inhumanos o degradantes. Sin embargo no fue hasta los años setenta cuando diversos grupos organizados de mujeres iniciaron las primeras acciones para identificar y hacer visible un problema que hasta entonces se había mantenido oculto y silenciado por considerarse privado: El problema de la violencia contra la mujer. A partir de entonces las asociaciones de defensa de los derechos humanos y los organismos internacionales se han manifestado para poner fin a la violencia de género, pudiendo considerar las últimas tres décadas las más fecundas en el reconocimiento de los derechos de la mujer y en la lucha para la eliminación de la violencia contra la mujer (Junquera, 2004, p.11).

As Delegacias especializadas no atendimento às Mulheres, DEAM² foram criadas em 1988 para atender as

\footnotetext{
1 Educação de gênero diz respeito aos processos informais e formais elaborados para transmissão da cultura, papéis sociais, valores, estereótipos, etc., que contribuem para manter a desigualdade entre sujeitos (mulheres, homens, homossexuais)

2 Delegacia da Mulher, doravante apenas DEAM
}

mulheres que eram discriminadas quando procuravam as delegacias convencionais. São poucas as instituições especializadas no acolhimento de gêneros. Localizam-se nas cidades pólos, isto é, em grandes centros próximos de outras cidades menores. No Pará, por exemplo, a DEAM de Tucuruí/PA, funciona mantida pela parceria, instituída através de convênio, entre a Secretaria de Trabalho e Promoção Social - SETEPS e a Prefeitura Municipal. Objetiva exercer as funções policial, judiciária e prestar assistência psicossocial à mulher em situação de violência doméstica, sendo procurada por mulheres das cidades de Breu Branco, Novo Repartimento, Goianésia, Baião, etc. (Pimentel, 2008a, 2008b, 2008c; Pimentel \& Silva, 2008a, 2008b). Já a DEAM de Belém atende aos municípios que formam a grande Belém (Marituba, Benevides, Mosqueiro, etc.)

As Delegacias implementaram a Lei $n^{0} 11340 / 06$ ou Lei Maria da Penha, que em setembro de 2010 completará quatro anos: "A lei tipifica a violência doméstica e familiar; estabelece as formas de violência doméstica contra a mulher como física, psicológica, sexual, patrimonial e moral" (Brasil, 2008, p.9). Sua promulgação modificou o tratamento dos homens agentes de violência instituindo a prisão preventiva ${ }^{3}$, pois a lei alterou alguns parágrafos do Código penal superando a aplicação de penas pecuniárias.

Mello e Dantas (2008) realizaram uma reflexão teórica sobre a violência doméstica e a Lei Maria da Penha analisando as proposições para o atendimento aos homens. Os autores criticam que apenas as teses de recuperação e reeducação são destacadas sem nenhuma menção à promoção da saúde, que para eles requer a prevenção como um eixo fundante:

No caso da violência contra a mulher, a prevenção seria, então, a aplicação de medidas que pudessem evitar o uso da violência nas relações afetivas entre um homem e uma mulher. A lei não busca isso. Apenas se dirige a esta relação para punir uma das partes, na forma exclusiva de privação da liberdade (...). Quanto à reeducação ou "recuperação", cremos que essa abordagem só aumenta a intolerância para com os homens que cometem violência, uma vez que os colocamos estigmatizados como a parte "podre" da sociedade que segue saneada pelos virtuosos que os tiram de circulação para formatá-los e, posteriormente, devolvê-los ao chamado "convívio social (Mello \& Dantas, 2008, pp. 83-84).

Ainda são parcas em volume as intervenções afirmativas com e para homens agentes de violência conjugal realizadas no País e no mundo (Cuschinir, 1998; Cuschinir \& Mardegan, 2001; Grossi, 2004). Na DEAM/

\footnotetext{
3 Conforme o tipo de delito cometido. A Lei Maria da Penha e o Código Penal são os indicadores usados pela autoridade policial e judicial para julgamento da violência domestica.
} 
Belém, o trabalho que fazemos situa-se nos campos da saúde e educação. As ações em saúde são de: a) triagem, b) psicodiagnóstico para avaliar e estabelecer diagnóstico diferencial para situações de violência sexual, pedofilia e transtornos neuróticos de personalidade, c) psicoterapia breve em grupo ${ }^{4}$, com cinco detentos voluntários. E as ações em educação de gêneros envolvem a formação de um grupo com 10 homens, em parceria com a Secretaria de Educação do estado ${ }^{5}$, visando à superação do analfabetismo e a inclusão digital associados à revisão das percepções e idéias sobre as relações entre gêneros. Neste campo, problematizamos as diferenças entre homens e mulheres; o sistema patriarcal de valores e prescrições hierarquizadas, etc. Ao longo dos meses, o trabalho em grupo foi possibilitando que os integrantes perguntassem, expressassem dúvidas e integrassem novas idéias as concepções de casamento e relações entre cônjuges.

O sistema prisional brasileiro requer uma reforma interna no que diz respeito à alocação dos presos conforme o delito, a gravidade e a reincidência. Os homens que praticam a violência doméstica e que são pais presentes na família não cometeram assaltos, roubos, homicídios, requerem detenção distinta da que tem os presos por outros crimes. Tal diferenciação reitera a importância das Delegacias da Mulher e requer para o Psicólogo uma formação em permanente atualização para que os profissionais alocados na instituição participem da elaboração de projetos de ressocialização dos detentos e conseqüente redução da violência doméstica.

Conforme Della Cunha (2004),

A violência na cidade se insere na rede de criminalidade moderna. Nas grandes cidades brasileiras, o mapeamento das cidades tornou-se o meio eficaz de segregação dos lugares de 'riqueza' e de 'pobreza', do ‘incluído' e do ‘excluído' em limites bem definidos e evidenciados entre espaços diferenciados de moradia, de serviços e de benefícios sociais (p. 65).

Brauner e De Carlos (2004) ponderam que o homem que comete violência doméstica se insere na rede da dominação patriarcal,

Da vinculação do poder a um gênero (o masculino). Nesse sentido, pode-se afirmar que a violência intrafamiliar possui como fundamento, não só a hierarquia entre os gêneros no caso da violência praticada pelo marido ou companheiro contra a esposa ou companheira, como também, o poder patriarcal, estigmatizado na figura do "homem da casa" (p. 136).

\footnotetext{
4 Duração de seis meses, uma sessão semanal com duas horas de duração facilitada pela pesquisadora e por um co-terapeuta voluntário.

5 Rafaela Paixão integra o grupo de estudos no mestrado em Psicologia da UFPA; é funcionária da SEDUC. Através de sua mediação, o programa Educação de Gêneros: alfabetização e inclusão digital estão em processo de implantação na UFPA/DEAM-Belém
}

A violência conjugal não é apenas vinculada a educação de gêneros dos homens. É também derivada de outros fatores de risco, por exemplo: é um subproduto do alcoolismo e da condição socioeconômica desfavorável; da ausência de suportes internos para conviver com as alterações no papel feminino derivadas da inserção pública e desvelamento da ideologia patriarcal, da ausência de políticas públicas para trabalho, saúde, etc.

Sobre os fatores de risco relacionados ao agente da violência conjugal, Junquera (2004) aponta:

Creencias irracionales respecto a la pareja, la familia y/o el maltrato; Falta de habilidades sociales y/o dependencia emocional respecto a la mujer; Rasgos de comportamiento obsesivo, control y/o celos; Toxicomanía y/o alcoholismo; Patologías mentales; Posesión y/o predisposición al uso de armas; Antecedentes penales; Incumplimientos de resoluciones judiciales penales; Antecedentes de maltrato a parejas anteriores; Amenazas de muerte a la víctima y/o de causar daño personal, familiar o social en su entorno (p. 34).

Considero que é de suma importância a implementação de mais Delegacias da Mulher e de reformas estruturais nas existentes, ou seja, efetivamente adequar à realidade física e de recursos humanos à prática das políticas da área descritas nos textos legais; equipamentos apropriados ao serviço e a exclusiva alocação de presos por violência conjugal ${ }^{6}$.

Feitas estas ponderações, situo a arquitetura do artigo: a) delinear o conceito de subjetividade em homens livres e detidos; b) resultados e análises da pesquisa feita em 2009 .

\section{Processos de Subjetivação de Homens Livres e Detidos}

A superação da violência conjugal requer ações de e para sujeitos livres. Para o casal se tornar livre é imprescindível a convivência com outros homens e com mulheres libertadores. A configuração dos processos de subjetivação masculinos requer um contexto social democrático e figuras amorosas significativas como suportes para o desenvolvimento e aprendizagens de sujeitos plenamente alforriados ${ }^{7}$.

O conceito de subjetividade integra os processos que caracterizam o mundo interno do individuo; o sistema complexo de significações e sentidos produzidos na vida cultural humana; a diferença ontológica dos elementos sociais, biológicos, ecológicos, etc. em um horizonte não linear, porém, em constante tensão e contradição (González-Rey, 2002).

\footnotetext{
Na DEAM-Belém além da violência conjugal há detentos por violência sexual, trafico de drogas, etc.

7 Diz respeito às varias formas de aprisionamento: psíquico, mental, social, econômico e à retenção do direito de ir e vir.
} 
O autor também pondera que os níveis constitutivos dos processos de subjetivação individual são: condição subjetiva; síntese da historia pessoal, social desenvolvimento na sociedade produzindo sentidos e significações, e ação/transformação da subjetividade social, entendida como sistema de relações estruturais, dialógicas de comunicação.

A síntese pessoal é uma elaboração difícil de estabelecer. Está relacionada, conforme Arendt (1999), à dificuldade que cada sujeito tem em replicar a pergunta: Quem é o homem, já que as respostas que costumamos dar a tal questão, apenas, observam o horizonte do QUE, ou das qualidades. Segundo a autora, "passamos a descrever um tipo ou personagem e acabamos perdendo de vista o que ele tem de singular e especifico" (Arendt, 1999, p. 194).

A convivência quando repleta de opressões, subterfúgios e frustrações impede que a explicitação de quem somos seja alcançada, bem como do surgimento de novas bases para as relações sociais. Se considerarmos que é "conveniente" ao estado, aos gestores das políticas de distribuição de recursos, à escola, a igreja e as famílias que os sujeitos permaneçam na "escuridão" do não esclarecimento, é possível supor que a violência conjugal continuará sendo abordada como uma questão privada do casal cuja responsabilidade ora é da mulher que não é submissa, ou do homem que é dominador, mantendo a dominação nas relações humanas.

Na revisão teórica sobre as Masculinidades, Grossi (2004) afirma:

Uma das principais definições da masculinidade na cultura ocidental para o gênero é que o masculino é ativo. Ser ativo, no senso comum a respeito de gênero, significa ser ativo sexualmente (...). Para a constituição do modelo de masculinidade hegemônica em nossa cultura, atividade não diz respeito apenas à sexualidade】 ela é também percebida positivamente como agressividade. Já na constituição da identidade de gênero na infância, observamos como o masculino se constitui pela hiperatividade dos meninos, que se confunde seguidamente com agressividade (p.11-12).

De acordo com Braz (2005): “Tem de se considerar que a subjetividade masculina baseada na força, no domínio e mesmo no machismo não é constituída sozinha já que o homem nasce e cresce num caldo cultural que o empurra para esse papel" (p 102).

Boris (2000), em investigação fenomenológica sobre a subjetividade masculina na contemporaneidade, ponderou que "não existe masculinidade única, mas que as manifestações viris apresentam-se numa tal diversidade que se torna praticamente impossível tratar de uma essência ou de uma identidade masculina universal" (p. 4).

Em síntese, abordar os processos de subjetivação de homens livres inclui reflexões sobre a nomeação, corporeidade, liberdade, autoestima, autoconceito, aceitação so- cial, trabalho, privacidade, moradia, escolaridade, intimidade, relações sociais e familiares, cidadania, etc. Quanto aos processos de subjetivação do homem detido (e apenado) muitos destes referentes são suprimidos da vivência cotidiana. Assim, usualmente, a expressão da subjetividade torna-se institucionalizada e instituída pela cultura do cárcere, um lugar polissêmico e multifacetado.

Conforme Della Cunha (2004):

O cidadão preso e condenado em decorrência de conduta delituosa é aquele temporariamente despojado do direito de exercício da liberdade individual, tendo os direitos civis e políticos e direitos sociais limitados e não terá em hipótese alguma, seja foragido ou ainda solto e não preso por reincidência criminal, direito a pleno gozo do status civitatis (p. 73).

A cultura do presídio, cujo padrão é estabelecido por regras tácitas, regulamentos e violência psicológica e física, determina os comportamentos e as moedas de troca para as interações sociais. Ela é um fator agregado aos processos de subjetivação do encarcerado. Um corolário que baliza os processos de subjetivação do encarcerado, para Della Cunha (2004, p. 64) "é a violência interindividual na qual indivíduos utilizam o recurso da força para atingir um ao outro, nomeia também aspectos institucionais de poder que estão no cerne de procedimentos violentos contra os cidadãos".

As interações sociais ainda acarretam a massificação e a despersonalização. De acordo com Fonseca, (2006),

Entre outros efeitos do aprisionamento, (...) cumpre destacar: a perda da identidade e a aquisição de nova identidade, o sentimento de inferioridade, o empobrecimento psíquico, a infantilização e a regressão. O empobrecimento psíquico acarreta, entre outras coisas, o estreitamento do horizonte psicológico, a pobreza de experiências, as dificuldades de elaboração de planos a médios e longo prazos. A infantilização e a regressão manifestam-se, entre outras coisas, através de dependência, busca de proteção, busca de soluções fáceis, projeção da culpa no outro e dificuldade de elaboração de planos (p. 543).

Na DEAM-Belém algumas regras que fazem parte da cultura da cadeia são: liderança de alguns detidos; não se apresentar sem camisa ante a visita das pesquisadoras e dos profissionais que realizam serviço voluntário religioso; oferecer tratamento "cortês" às autoridades femininas; repreender os colegas quando estes são "indelicados”. Parece-me que a lei interna, revela muito mais a assunção de um papel, a absorção da vigilância, (Foucault, 1987), que a evocação do modelo hegemônico de homens propostos por Connell (citado por Fialho, 2006) e a reconfiguração da ideologia que carregam sobre as relações entre mulher e homem. 
Os dois homens ${ }^{8}$ que se destacaram a época da coleta, na liderança, me pareceram que o fizeram não por constituírem um grupo social dominante, mas por uma tentativa intencional de organizar e melhorar a vida na cadeia:

“(...) tento retirar deles a idéia de que isto aqui é uma prisão. Ser líder é tentar dar uma palavra, apoio, ajudar a esfriar a cabeça e fazer um acompanhamento do colega, eu sou líder, e oriento o fulano para ajudar no trabalho." (Q1)

\section{Metodologia}

Algumas premissas que orientam a pesquisa qualitativa $^{9}$ são: considerar a unicidade e complexidade do sujeito estudado; a presença da teoria como instrumento a serviço do pesquisador em todo o processo interpretativo, não como um conjunto de categorias a priori capazes de dar conta dos processos únicos e imprevistos da existência.

Este relato de pesquisa deriva de estudo realizado na DEAM, em Belém do Pará. Os procedimentos incluíram revisão bibliográfica, leitura de documentos e observação participante para conhecer a estrutura e o funcionamento da Delegacia; obtenção da assinatura dos dirigentes da instituição e dos sujeitos para o consentimento de pesquisa e aplicação de um questionário a dez homens com escolaridade nível fundamental, primeiro e segundo graus, todos incompletos. As questões abordaram a perspectiva de masculinidade; o modelo de configuração da subjetividade masculina, a expressão afetiva dos sentimentos e a conformação das idéias acerca da virilidade. Foram reorganizadas em eixos temáticos.

Todos os informantes tiveram sua identidade preservada e a pesquisa atendeu as deliberações do Comitê de Ética do Centro de Ciências da Saúde da UFPA. A composição da amostra foi orientada tomando por base, Turato (2003) que asseverou o caráter intencional e a indicação de informantes pela rede de contato dos pesquisadores. Serão apresentados através do uso de um código que inclui letras e números: Q1 até Q10.

Os questionários foram apostos na cadeia da DEAM na área destinada ao banho de sol. As perguntas abertas visaram identificar as significações que os homens detidos atribuíram à masculinidade. $\mathrm{O}$ espaço é um lugar apertado, fedido e quente, confirmando as ponderações acerca da sanidade, a semelhança do que observou Fonseca (2006), "a partir do período imperial, tem inicio uma preocupação com a salubridade das prisões brasileiras, que são consideradas lugares sujos, insalubres, úmidos e fétidos" (p. 535). No lugar não há cadeiras, assim,

\footnotetext{
8 Os informantes foram identificados por código composto por letras e números: Q1 até Q10

9 Pesquisa qualitativa: no texto, PQ
}

a realização se deu com os homens em pé e de cócoras. Por norma de segurança, determinada pela Secretaria de Estado, a cela permaneceu aberta, e a coleta se deu sob a vigilância policial.

Para Foucault (1987), a prisão,

(...) local de execução da pena, é ao mesmo tempo ponto de observação dos indivíduos punidos. Em dois sentidos. Vigilância é claro. Mas também conhecimento de cada detento, de seu comportamento, de suas disposições profundas, de sua progressiva melhora; as prisões devem ser concebidas como um local de formação para um saber clínico dos condenados (pp. 208-209).

Dois detentos ${ }^{10}$ funcionaram como apoio, auxiliando-me na distribuição e recolhimento do Termo de Consentimento Livre e Esclarecido. Para as análises recorri à literatura que trata da subjetividade masculina e gênero cotejando os dados na medida das possibilidades hermenêuticas. A organização dos resultados foi por temáticas.

\section{Resultados e Discussão}

\subsection{Perfil do grupo}

Faixa etária: 28 a 50 anos. Dez homens com educação primária e secundária incompletas. Desses, 4 abrangem o intervalo etário dos 23 aos 29 anos; 3 pertencem ao de 31 aos 30 anos, e 3 integram o dos 45 aos 50 anos.

Ocupações: flanelinha, pedreiro, lavador de carro, balconista, agricultor, reciclador, carpinteiro, marceneiro, cozinheiro, pizzaiolo, vigilante, motorista, serviços gerais, engraxate, autônomo e artesão. Vale comentar que alguns homens apontaram que tem várias ocupações e que fazem o serviço que aparecer, o que significa que não há escolha profissional devido o baixo grau de escolaridade e de qualificação, fatores agravantes da prática violenta no âmbito da casa.

\subsection{Motivos da detenção}

Na DEAM é alta a rotatividade dos detentos devido ao impetramento de habeas-corpus ${ }^{11}$. Também há protocolos incompletos derivados de outras Delegacias. Deste modo, algumas informações ficaram indisponíveis no levantamento de dados.

\footnotetext{
${ }^{10}$ Fiz um contato prévio com ambos em momento anterior em que foram entrevistados.

11 Parágrafo único do capitulo II da Lei Maria da Penha determina que o juiz poderá revogar a prisão preventiva se, no curso do processo, verificar a falta de motivo para que subsista, bem como de novo decretá-la, se sobrevierem razões que a justifiquem. (Brasil, 2008, p. 24)
} 
Q1 foi detido por ter feito ameaças a esposa; Q2 bateu na enteada, porém foi detido por ter abusado da menor; Q3 bateu na irmã; Q5 feriu com faca a esposa; Q7 foi detido em flagrante por agressão à companheira; Q9, por tráfico de entorpecentes, este é um caso particular devido à condição do detento de filho de policial. Por correr risco de morte, foi transferido de uma delegacia comum para a DEAM. Os demais não informaram.

\subsection{Processos de subjetivação}

Sobre os modelos, a referência para aprendizagem da masculinidade, para seis informantes, unicamente, foi à mãe; enquanto que a exclusividade do pai na função de modelo foi apontada apenas por dois. Para os outros dois, o pai e a mãe (mesmo que de criação), foram às referências.

Q2: a partir dos 06 anos passou a viver somente com a mãe que é funcionária municipal. Sentiu muita tristeza com a separação dos pais,

"Foi uma grande dor. Ele saiu de casa porque ele não gostava que a minha mãe bebesse, ela bebe muito. Depois ela parou quando descobriu que era diabética. A gente aconselha muito ela a parar de beber, eu e meus irmãos. Ela tem um problema com o meu padrasto, ele é macumbeiro, ele faz feitiçaria pra ela. A gente aconselha muito ela pra ir pra igreja."

Tem contato com o pai, de quem recebe conselhos, “(...) Ele sabe que eu to preso aqui, ele quer vir aqui." Revelou que se sentiu zangado com a mãe, pela separação, “(...) Eu gosto muito do meu pai, meu pai não é de beber, não bebe, não fuma, quem bebe é ela."

Q5 tinha mãe solteira que trabalhava fora como lavadeira, a quem ajudava entregando a roupa lavada na casa da contratante.

Q9 teve mãe solteira. É único filho. Sempre viveu com a avó e as tias. A mãe trabalhava fora, na polícia. Tinha dois tios, um padre que vivia no seminário, e outro, casado; não teve contato cotidiano com ambos, portanto, configurou sua aprendizagem acerca da masculinidade com as mulheres. Por ter muita mulher em casa, não participava das atividades domésticas: lavar louça, comida. Tinha a tarefa de lavar o banheiro, levar o lixo pra fora. Essas tarefas pesadas. Quando era garoto, até meus nove anos, não fazia nada. Brincava na rua, jogava futebol, pegava pipa. Depois comecei a auxiliar, tinha corpo, entendimento pra fazer, comecei a auxiliar no serviço de casa.

Em seu discurso, o informante mostrou a clássica divisão de tarefas entre homens e mulheres bem como a sexualização dos serviços: pesados e domésticos. Além disso, revelou que sua mãe estava abalada com sua prisão, artigo 33, tráfico de entorpecentes: “Sou usuário des- de os quinze anos, e há dois meses comecei a traficar, por falta de trabalho."

Quanto ao modelo para aprendizagem da masculinidade é possível supor que a configuração da autoimagem dos seis homens que tiveram a mãe como modelo reflete que a presença do elemento feminino determinou a formação da subjetividade, da socialização, normas de inserção existencial, fluidez ou retração da expressão dos sentimentos e formas de lidar com o conflito. Também se deve aos papéis sociais da mulher, por exemplo, chefiar a família sem a presença do pai: “(...) A relação com a mãe parece, sem duvida, ser um dos constituintes do masculino, influenciando a imagem e o relacionamento posterior com outras mulheres e mesmo com outros homens" (Boris, 1999, p. 3).

O pai foi apontado como uma figura que transmitia orientações incongruentes, por exemplo, indicar ao filho a importância do trabalho e da formação do caráter, e concomitantemente agir de modo autoritário, exigente, "brabo", permitindo-se ter várias mulheres e descuidar da casa, pois estava na farra. (Q3, Q6, Q10).

O conjunto das alterações na vida provocadas pelas mudanças do capital financeiro, da globalização da economia, dos valores, necessidades, formas de trabalho, abrangem a falta de convivência familiar e de intimidade. Por sua vez, a família ${ }^{12}$ encontra-se esfacelada, sem suportes comunitários, sem presença materna e paterna o que instala para os filhos, meninos e meninas, descuido, insegurança, referentes inadequados para a socialização. Instalada a ciranda do consumo de bens e de pessoas cria o engolfamento da humanização e a circularidade da violência doméstica.

No Anexo I, Quadro 1 - Processos de subjetivação (masculinidades; modelos; afetividade; virilidade), apresento uma síntese de todas as respostas de Q1 a Q10.

\subsection{Compreensão da violência}

Q1: "Eu creio que seja tratar as pessoas mal, bater, tentar humilhar alguém; eu acho que isso é a violência;"

Q2: "Tentar bater nos outros, achar que é melhor muitos quebram a cara. Eu já vi muita gente, na minha área, mal começava a confusão, caia logo ali."

Q3: "A rua me ensinou, se chegar comigo eu bato logo, porque paciência não é pra qualquer um. Nada me assusta, eu sempre espero o que vier, eu sempre tou preparado. Eu achei que quando eu caísse aqui, eu ia encontrar um grupo - ah, tu bate em mulher, agora eu quero ver bater em homem. E eles iam ver que eu

\footnotetext{
${ }^{12}$ A família nuclear e os arranjos familiares: monoparentais, homossexuais, recasamentos são formas de organização atual dos vínculos conjugais.
} 
ia botar pra brigar aqui dentro, ou até me tirar, ou eu sair desmaiado. Até onde eu agüentar, mas tanto faz mulher, homem. Eu revidei uma coisa que eu levei."

Q4: "O que eu entendia sobre violência? Eu vim a entender dessa lei agora. Eu não entendo de lei de homem pra mulher. Eu revidei pra ver o que ia acontecer. Eu cai aqui e não to arrependido."

Q5: "Bater; acho que até esculhambar muito forte; também fazer coisas, pegar pessoa forçada, etc. Essas coisas que a gente pode descobrir ainda. Só de tentar ir pra cima de uma pessoa, já tá com violência. Só da pessoa já colocar aquilo dentro dele, que vai fazer aquilo, se colocar de fora, como fazer, digamos uma ação, claro que ele vai colocar em prática. Aquilo também vira uma violência, se não souber se controlar."

Nos discursos, identificamos a descrição de indicadores das violências psicológica, física, e sexual; bem como uma referência estereotipada da paciência como um traço qualificador da subjetividade feminina. Sobre a possível responsabilidade do agente a respeito do ato violento, no discurso de Q5 há uma sugestão da intenção de realizá-lo. A responsabilização é indispensável à atualização do comportamento e a eliminação da violência conjugal na medida em que elimina as usuais desculpas atribuídas pelos companheiros ou maridos as agressões e abusos cometidos.

\section{Considerações Finais}

Sobre a participação do pai na configuração da subjetividade, em pesquisa sobre a paternidade (Pimentel, 2008a, 2009), os informantes portugueses e brasileiros afirmaram que o pai cuidadoso é aquele que expressa afetividade, o que abrange as ações de dar amor, afeto, carinho, ser meigo, atencioso, companheiro, amigo, amoroso e superpai, ser bom, ótimo, dedicado. Tal referência não apareceu no discurso dos detentos.

Das modalidades de violência conjugal praticadas, a física foi a mais citada. Sugere que fez parte da aprendizagem dos meninos. O comportamento violento dos informantes, a instrução reduzida, cultura massificada, pouco diálogo e economicamente desfavorecidos, pareceu forjada, entre outros fatores pela inadequada interpretação que fizeram das orientações feitas pela mãe, tias, irmãs. Por exemplo: controle dos impulsos agressivos; resistência ativa e bruta à abordagem de outro homem, na rua. É importante ressaltar que a socialização dos meninos é orientada ambiguamente: seja forte, viril e não chore (Grossi, 2004)

A incidência da modalidade violência psicológica entre os informantes foi bastante confirmada, isto é todos sabem humilhar, desqualificar, xingar; enquanto que as formas de violência moral e a patrimonial não foram destacadas Talvez, a inabilidade verbal dos informantes, a recorrência a força física, a falta de paciência, a vontade de romper com a sensação de inferioridade ante a sua mulher sejam fundamentos da incidência da violência física.

As idéias da virilidade permanecem clássicas; ao pênis foram atribuídas as funções de: a) afirmação da masculinidade: Q1, Q2, Q5 e Q6; b) prazer: Q2, Q7, Q8, Q9; c) reprodução: Q3 e Q10.

As pesquisas sobre Masculinidades apontam que há uma inegável alteração na configuração da subjetividade referente aos papéis de pai e de marido, não do homem detido. Conforme Grossi (2004):

A categoria "processo de mudança" me parece mais adequada para pensar o momento pelo qual estão passando homens e mulheres em suas relações e constituições de processos identitários. Algumas destas "novas" masculinidades se afastam do modelo tradicional de força que definia o homem. Nestes novos modelos seria valorizada a inteligência, a sensibilidade e a capacidade de lidar com novas tecnologias. Alguns se perguntam se os "novos" homens seriam menos machistas? A resposta é complexa, pois ela exige, mais uma vez, contextualização das diferentes relações sociais nas quais as identidades de gênero são produzidas (p. 29).

Nossa pesquisa é reveladora, contudo, mais investigações qualitativas com homens detidos são necessárias, já que o cárcere requer procedimentos e instrumentos compatíveis aos limites institucionais para as normas de segurança em que a contenção por algemas dos informantes é norma, bem como o impedimento de contatos privados. Os dados não sugeriram nenhum indicador da categoria "processo de mudança" no discurso dos informantes; deste modo não é possível afirmar ou tratar os homens a partir da idéia universal que a "crise" da masculinidade é vivenciada por todos.

A psicologia clínica socialmente engajada, isto é que inclui intervenção em grupo e a inclusão dos diversos contextos sociais no manejo terapêutico (Pimentel, 2008d) é uma ferramenta de contribuição ao enfrentamento da violência doméstica. É praticada por profissionais que superam o mito da medicalização, patologização e identificação do sofrimento como algo eminentemente psicológico:

A despatologização da condição feminina, característica central dos modelos terapêuticos feministas, é também fulcral na abordagem feminista do fenômeno da violência contra as mulheres na intimidade. Ao substituir o primado dos constructos intrapsíquicos na caracterização das vítimas pelo primado dos factores contextuais, as terapias feministas re-localizam a gênese da violência e invalidam o mito da responsa- 
bilidade e da culpabilidade feminina no cometimento deste tipo de actos criminosos. Ao invés de centrar a sua actuação na redução da sintomatologia decorrente da vitimização, a intervenção feminista em espaços terapêuticos procura reabilitar as potencialidades das vítimas, torná-las mais competentes do ponto de vista das suas performances sociais e orientá-las face aos recursos institucionais disponíveis. As Terapias feministas são por isso práticas terapêuticas que fomentam a resiliência e a autonomia das mulheres vítimas, numa lógica de intervenção social alargada e colaborativa, na qual os esforços de coligação com a comunidade são uma constante. (Neves \& Nogueira, 2003, p.16)

Para reduzir a violência conjugal é oportuno articular intervenções no campo da educação de gêneros e da saúde, sustentadas em princípios tais como: renovar a cultura em que os homens continuam socializados para integrar grupos e formar arranjos conjugais; edificar formas horizontais de distribuição do poder entre os integrantes das famílias e desvelar os mecanismos da violência doméstica. No âmbito dos processos de subjetivação fomentar a expressão dos sentimentos e da comunicabilidade evitando que meninos se desenvolvam de modo dual e deliberadamente ajustado.

Os detentos por violência conjugal na DEAM-Belém assemelham-se ao contingente de homens presentes nas diversas regiões do Brasil, o que indica que intervenções coletivas em educação de gêneros e saúde (ética de gêneros e do cuidado, psicoterapia breve em grupo, orientação, psicodiagnóstico, etc.) são necessárias para contribuir para a redução do cenário desfavorável que atinge as mulheres e seus filhos e reedita o circuito da opressão.

\section{Referências}

Arendt, H. (1999). A Condição Humana. Rio de Janeiro: Forense Universitária.

Boris, G. D. J. B. (1999). Fragmentos do discurso masculino. VII Encontro Nacional de Gestalt-Terapia / IV Congresso Nacional da Abordagem Gestáltica. Goiânia: ITGT.

Boris, G. D. J. B. (2000). Falas masculinas ou Ser homem em Fortaleza: Múltiplos recortes da construção da subjetividade masculina na contemporaneidade. Tese de doutorado em Sociologia, UNIFOR, Fortaleza.

Brasil (2008). Lei no 11.340, de 7 de agosto de 2006 (Lei Maria da Penha). Secretaria Especial de Políticas para as Mulheres. Brasília.

Brauner, M. C. \& De Carlos, P. P. (2004). A Violência Intrafamiliar sob a perspectiva dos direitos humanos, direitos humanos e adoção. Em G.Maluschke, J.Bücher-Maluschke \& K. Hermanns, Direitos Humanos e violência: desafios da ciência e da prática (pp. 133-148). Fortaleza: Fundação Konrad Adenauers.
Della Cunha, D. B. (2004). Violência urbana, segurança pública e direitos humanos. Em G. Maluschke, J. Bücher-Maluschke \& K.Hermanns, Direitos Humanos e violência: desafios da ciência e da prática (pp. 63-76). Fortaleza: Fundação Konrad Adenauers.

Braz, M. (2005). A construção da subjetividade masculina e seu impacto sobre a saúde do homem: reflexão sobre justiça distribuitiva. Psicologia e saúde colectiva, 10(1), 97-104.

Conrado, M. P. (2001). A fala dos envolvidos sob a ótica da lei: um balanço da violência a partir da narrativa de vítimas e indiciados em uma delegacia da mulher. Tese de Doutorado em Sociologia, Faculdade de Filosofia, Letras e Ciências Humanas, São Paulo, Universidade de São Paulo.

Cuschinir, L. (1998). Masculino, como ele se vê. São Paulo: Ed. Rosa dos Tempos.

Cuschinir, L., \& Mardegan Jr., E. (2001).O homem e suas máscaras. Rio de Janeiro: Campus.

Fialho, F. M. (2006). Uma Crítica ao Conceito de Masculinidade Hegemônica. Disponível em http://www.ics.ul.pt/.

Fonseca, K. P. (2006). (Re) Pensando o crime como uma relação de antagonismo entre seus autores e a sociedade. Psicologia Ciência e Profissão, 26(4), 532-547.

Foucault, M. (1987). Vigiar e Punir. Petrópolis: Vozes.

González-Rey, F. L. (2002). Pesquisa Qualitativa em Psicologia: Caminhos e Desafios. São Paulo: Thomsom/Pioneira.

Grossi, M. P. (2004). Masculinidades: Uma Revisão Teórica. Antropologia em primeira mão. Programa de Pós Graduação em Antropologia Social, Universidade Federal de Santa Catarina, Florianópolis: UFSC.

Junquera, M. L. V. (2004). Guía de intervención social ante los malos tratos (volumen I). Gobierno de La Rioja. Disponível em http://pt.scribd.com/doc/23351735/guiaintervencion-MUJERES-MALTRATADS, acesso em abril de 2008.

Mello, R. P., \& Dantas, B. M. (2008). Posicionamentos Críticos e éticos sobre a violência contra as mulheres. Psicologia \& Sociedade, 20, Edição Especial, 78-86,

Neves, S., \& Nogueira, C. (2003). A psicologia feminista e a violência contra as mulheres na intimidade: a (re)construção dos espaços terapêuticos. Psicologia \& Sociedade, 15(2), 43-64.

Pimentel, A. (2008a). Cuidado paterno: enfrentamento da violência. São Paulo: Summus.

Pimentel, A. (2008b). Projeto de pesquisa: estudo da subjetividade masculina e feminina: violência, conjugalidade e paternidade. Belém: UFPA/Núcleo de Pesquisas Fenomenológicas.

Pimentel, A. (2008c). Construção Psicológica da subjetividade masculina. Em A. Pimentel \& A. C. G. Moreira (Orgs.), Psicologia, Instituição e Cultura (pp. 135-140). Belém: Amazônia Editora. 
Pimentel, A. (2009). Formas de exercer a paternidade em Belém e Évora. Revista da Abordagem Gestática [online]. 15(1), pp. 36-41.

Pimentel, A., \& Silva, C. F. (2008a). Violência psicológica contra a mulher paraense. Belém: UFPA/Núcleo de pesquisas

Pimentel, A., \& Silva, C. F. (2008b). Violência psicológica contra a mulher em Tucuruí-PA: pesquisa em gestalt-terapia. Belém: UFPA/Núcleo de Pesquisas Fenomenológicas.

Turato, E. (2003). Tratado de metodologia de pesquisa clínico qualitativa. Petrópolis: Vozes.
Adelma Pimentel - Doutora em Psicologia, com Pós-Doutorado no âmbito da Psicologia e Psicopatologia do Desenvolvimento em Évora, Portugal. É Pesquisadora e Docente na Faculdade e Mestrado em Psicologia da Universidade Federal do Pará, sendo líder do Núcleo de Pesquisas Fenomenológicas e Diretora da Faculdade de Psicologia da UFPA. Endereço Institucional: Universidade Federal do Pará, Mestrado em Psicologia Clínica e Social. Av. Augusto Correia, s/n (Guama). CEP: 66075.110. Belém, PA. Email: adelmapi@ufpa.br

Recebido em 18.06.10 Primeira Decisão Editorial 15.09.10 Aceito em 20.10.10

\section{Anexo I}

Quadro 1 - Processos de subjetivação (masculinidades; modelos; afetividade; virilidade)

\begin{tabular}{|c|c|c|c|c|c|c|c|c|c|c|}
\hline & Q1 & Q2 & Q3 & Q4 & Q5 & Q6 & Q7 & Q8 & Q9 & Q10 \\
\hline SER HOMEM & $\begin{array}{l}\text { Ter autori- } \\
\text { dade }\end{array}$ & $\begin{array}{l}\text { Palavras; ação; } \\
\text { trabalho }\end{array}$ & $\begin{array}{l}\text { Forma física, } \\
\text { forma de Deus }\end{array}$ & $\begin{array}{c}\text { Esteio da } \\
\text { casa }\end{array}$ & Manter moral & $\begin{array}{c}\text { Cumprir seu } \\
\text { dever }\end{array}$ & $\begin{array}{l}\text { Se considerar } \\
\text { superior a alguns } \\
\text { atos da femi- } \\
\text { nilidade; força } \\
\text { física; fisionomia. }\end{array}$ & $\begin{array}{c}\text { Homem de } \\
\text { nascença }\end{array}$ & $\begin{array}{c}\text { Ter voz } \\
\text { grossa, força } \\
\text { física }\end{array}$ & $\begin{array}{c}\text { Ser mais forte } \\
\text { em aspecto, } \\
\text { ter caráter, } \\
\text { ensinar } 0 \\
\text { bem. }\end{array}$ \\
\hline MODELO & Mãe & $\begin{array}{l}\text { Mãe de criação, } \\
\text { pai, Jesus }\end{array}$ & Pai & Mãe & Mãe & Pai & Mãe & Mãe & Mãe & Pai \\
\hline $\begin{array}{l}\text { GOSTOU DE } \\
\text { APRENDER }\end{array}$ & $\begin{array}{l}\text { Respeitar } 0 \\
\text { próximo }\end{array}$ & $\begin{array}{l}\text { Não pegar nada } \\
\text { do próximo, pagar } \\
\text { as dívidas em dia; } \\
\text { com Jesus, andar } \\
\text { no caminho dele }\end{array}$ & $\begin{array}{l}\text { Trabalho, caráter, } \\
\text { confiança em } \\
\text { Cristo, humildade } \\
\text { e temor }\end{array}$ & Acertos & Educação & $\begin{array}{l}\text { Trabalhador } \\
\text { honesto }\end{array}$ & Sinceridade & $\begin{array}{l}\text { Viver com } \\
\text { educação }\end{array}$ & $\begin{array}{l}\text { Garra, } \\
\text { determina- } \\
\text { ção, respon- } \\
\text { sabilidade, } \\
\text { respeito }\end{array}$ & $\begin{array}{l}\text { Honesto, } \\
\text { caráter, } \\
\text { respeito }\end{array}$ \\
\hline $\begin{array}{l}\text { NÃO GOSTOU DE } \\
\text { APRENDER }\end{array}$ & $\begin{array}{l}\text { Apanhar/ } \\
\text { bater em } \\
\text { criança }\end{array}$ & & $\begin{array}{l}\text { Autoritarismo, } \\
\text { exigência, estupi- } \\
\text { dez, brabeza }\end{array}$ & Erros & $\begin{array}{c}\text { Fazer tarefas } \\
\text { de casa }\end{array}$ & $\begin{array}{l}\text { Mulherengo, } \\
\text { farrista }\end{array}$ & $\begin{array}{l}\text { Paciência, modo } \\
\text { de agir. }\end{array}$ & Ficar só & $\begin{array}{l}\text { Gostou de } \\
\text { tudo }\end{array}$ & $\begin{array}{l}\text { Mulherengo } \\
\text { demais }\end{array}$ \\
\hline $\begin{array}{c}\text { FATOR } \\
\text { INDISPENSÁVEL } \\
\grave{A} \\
\text { MASCULINIDADE }\end{array}$ & $\begin{array}{l}\text { Pênis: eu } \\
\text { tenho, eu } \\
\text { sou homem. }\end{array}$ & $\begin{array}{l}\text { Pênis, pelo no } \\
\text { corpo, andar, agir }\end{array}$ & $\begin{array}{l}\text { Responsabili- } \\
\text { dade sobre a } \\
\text { família: sustento, } \\
\text { proteção, diálogo, } \\
\text { educação }\end{array}$ & $\begin{array}{l}\text { Há um, mas } \\
\text { não apontou }\end{array}$ & $\begin{array}{l}\text { Mostrar que } \\
\text { sou homem }\end{array}$ & $\begin{array}{l}\text { Dar segurança, } \\
\text { assistência, } \\
\text { compreensão, } \\
\text { amor à esposa e } \\
\text { filhos, dar bons } \\
\text { exemplos. }\end{array}$ & $\begin{array}{l}\text { Autodefesa, de- } \\
\text { fender o cônjuge, } \\
\text { se autodefender } \\
\text { verbalmente }\end{array}$ & Não há & $\begin{array}{c}\text { Força física } \\
\text { e sentar } \\
\text { de pernas } \\
\text { abertas }\end{array}$ & $\begin{array}{l}\text { Há um; não } \\
\text { especificou }\end{array}$ \\
\hline $\begin{array}{c}\text { IMPORTÂNCIA DO } \\
\text { PÊNIS }\end{array}$ & $\begin{array}{l}\text { Indicar a } \\
\text { masculini- } \\
\text { dade }\end{array}$ & $\begin{array}{c}\text { Saciar os prazeres } \\
\text { da carne }\end{array}$ & Ter filhos & $\begin{array}{l}\text { Penetração } \\
\text { sexual }\end{array}$ & $\begin{array}{l}\text { Prova que sou } \\
\text { homem }\end{array}$ & $\begin{array}{l}\text { Definir o homem } \\
\text { da mulher. }\end{array}$ & União conjugal & Sensação & $\begin{array}{c}\text { Dar prazer } \\
\text { à mulher } \\
\text { (saber usar) }\end{array}$ & Reprodução \\
\hline AFETIVIDADE & $\begin{array}{l}\text { Carinho pela } \\
\text { família, se } \\
\text { dá bem com } \\
\text { a mulher }\end{array}$ & $\begin{array}{l}\text { Viver bem, diálogo, } \\
\text { carinho, conver- } \\
\text { sar, passear, orar, } \\
\text { fazer o que Deus } \\
\text { pede }\end{array}$ & $\begin{array}{l}\text { Compreensão, } \\
\text { diálogo, atenção, } \\
\text { confiança, } \\
\text { participação na } \\
\text { educação }\end{array}$ & $\begin{array}{c}\text { Ser uma boa } \\
\text { pessoa, com- } \\
\text { panheirismo, } \\
\text { conversa, } \\
\text { respeito, } \\
\text { amizade }\end{array}$ & $\begin{array}{c}\text { Afeto, } \\
\text { compreensão, } \\
\text { compartilhar } \\
\text { junto, respeito } \\
\text { no lar }\end{array}$ & $\begin{array}{l}\text { Respeito, } \\
\text { atenção, } \\
\text { carinho, amor, } \\
\text { responsabilidade } \\
\text { sinceridade. }\end{array}$ & $\begin{array}{l}\text { Se sentir mais } \\
\text { amável; confian- } \\
\text { ça; sinceridade; } \\
\text { amor; respeito; } \\
\text { livre arbítrio }\end{array}$ & $\begin{array}{l}\text { Amor, } \\
\text { comunica- } \\
\text { ção }\end{array}$ & $\begin{array}{l}\text { Respeito } \\
\text { mútuo, } \\
\text { carinho, } \\
\text { amor, enten- } \\
\text { dimento }\end{array}$ & $\begin{array}{l}\text { Amor, respei- } \\
\text { to, considera- } \\
\text { ção, carinho, } \\
\text { agradar }\end{array}$ \\
\hline
\end{tabular}

